\title{
correspondence
}

\section{The militant scientist}

A recent book review described the philosopher Thomas S. Kuhn as "one of the two leading anti-'science' writers of the twentieth century" (Penny (2005) EMBO Rep 6: 511). Kuhn's theory that science progresses in fits and starts has sparked debates ever since its initial publication (Kuhn (1962) The Structure of Scientific Revolutions. Chicago, IL, USA: University of Chicago Press). The theory can be said to be questionable, its conclusion highly speculative and its interpretation unlikely to reflect the true nature of scientific activity. If stronger dissent must be expressed, the theory can be said to be without foundation, unsupported by available observations and unsubstantiated by known facts. In fact, the whole thing can be viewed as complete nonsense if one so wishes. The label that was chosen, however, is 'antiscience'. In my opinion, this wording carries little argumentative value; it merely reveals the rise of militancy among scientists.

Labels such as 'anti-science' are the expression of an 'us against them' mentality, one of the consequences of a wave of radicalism sweeping Western societies. O ne does not need to be an attentive observer to realize that intellectual positions are now becoming more polarized. Historically, this has often been the case after periods of rapid social change: civil and religious strife succeeded the Renaissance, ardent nationalism followed the French revolution. It may be argued that, for the most part, the present polarization of society has its origin in the reform movements of the 1960s. Obviously, science is not excluded from historical cycles, and the rhetoric of conflict has entered the scientific discourse. Unfortunately, the rise of militants often leads to orthodoxy, even if it is only for the sake of the cause.

Although not explicitly named in the book review, I suspect the other leading anti-science writer is someone who, like Kuhn, stressed the role of the creative individual-as opposed to the scientific community-in moving science ahead. This emphasis obviously clashes with the militant's view that science is a system with a value that is measured by its usefulness to the community and that, above all, must be defended against competing systems.

The example put forward to dismiss Kuhn as 'anti-science' is his proposal that the age of a scientist determines his acceptance of new scientific theories. However, Kuhn quotes Max Planck, that "a new scientific truth does not triumph by convincing its opponents and making them see the light, but rather because its opponents eventually die, and a new generation grows up that is familiar with it" (Kuhn, 1962). I trust we can agree that Planck can hardly be accused, as was Kuhn, to have "had little knowledge of how science either does, or should, function" (Penny, 2005).

The debate over what constitutes science and anti-science is a tricky one and reminds us of the dichotomy of good and evil. In this regard, I have often noticed that those who actually do good spend very little time defining the nature of benevolence itself. By contrast, and contemporary politics vindicate me on this point, those who constantly invoke good to justify their actions end up doing very little. The same may apply in science. I venture to suggest that the militant scientist, who is preoccupied with defining what is science and what is not, actually hinders its progress.

\section{Christian Lanctôt isat the Ludwig- Maximilians-Universität, Munich, Germany. E-mail: christian.lanctot@Irz.uni-muenchen.de doi: 10.1038/sj.embor.7400519}

